\title{
EFFECT OF CEREAL BINDER, MOISTURE, AND CLAY CONTENTS ON THE FUNCTIONAL PROPERTIES OF CLAY-BONDED CORE AND MOULDING SANDS
}

\author{
E.O. Olakanmi ${ }^{1 *}$, S.G. Aiyeru ${ }^{2}$, and P.I. Idalu ${ }^{3}$ \\ Department of Mechanical Engineering, \\ Federal University of Technology, Nigeria. \\ ${ }^{1}$ eyinice@yahoo.com, ${ }^{2}$ egasaiyeru1@yahoo.com, ${ }^{3}$ ilimho@yahoo.com
}

\begin{abstract}
The effects of alikama cereal and clay binder additions and moisture contents on the functional properties of clay-bonded core and moulding sands are explored. The outcomes suggest that improved functional properties resulting from the effective bonding properties of the cereal and clay binders were obtained when a certain optimum level of each of the additives was used with the optimum percentage of cereal binder and tempering water. This work establishes the viability of the cereal binder addition in a clay bonded core and moulding sand mixes for industrial and laboratory applications.
\end{abstract}

\section{OPSOMMING}

Die uitwerking van byvoegings van graan- en kleibinders en voginhoud by gietvormklei vir gebruik by gietprosesse word ondersoek. Die resultate dui op verbeterde funksionele eienskappe wat voortspruit uit optimum benutting van bestanddele.

${ }^{*}$ Corresponding author 


\section{INTRODUCTION}

In an attempt to develop locally available bonding clays and moulding sands for foundries with a view to conserving our foreign exchange, refractory clay and silica sand deposits in several parts of Nigeria were identified and their properties investigated. For example, Olakanmi and Khan [1] characterised the moulding and core-making properties of locally available foundry sands in Niger, Kwara, Oyo, and Osun States of Nigeria. They discovered that Chanchaga sand was the most suitable for core-making owing to its lower clay content, while Igbokoda and Ire-Akari sands were considered suitable for moulding purposes. Furthermore, Loto [2] explored the effects of cassava flour and coal dust additions on the mechanical properties of synthetic moulding sand, and found an overall improvement in the mechanical properties of the sand mixtures for both the cassava flour and coal dust additions, although with a slight tolerable decrease in toughness. Ibitoye and Afonja [3] investigated the viability of Ife potter's clay as a substitute for the imported bentonite, and concluded that the behaviour of Ife potter's clay-bonded sand and bentonite-bonded sand was comparable.

Meanwhile, cereal binders such as corn flour had been used in foundries to improve the green strength of moulding sands through the formation of gelatinous bond. Other benefits obtainable when cereal binders are added to moulding and core mixtures are improvement in the charring capacity and collapsibility of the mixtures after their exposures to the heat of casting. Alikama, a cereal binder, which is cultivated abundantly in Nigeria, is expected to provide the necessary improvement in the functional properties of core and moulding mixtures. It is therefore considered pertinent to explore its functional properties in order to be able to characterise its viability for further industrial and laboratory applications. It is expected that the positive outcome of this study will be economically beneficial to the foundry sub-sector in Nigeria. In addition, this work is an attempt to develop local clay as a binder for synthetic core and moulding sands and as a substitute for imported bentonite clays.

\section{MATERIALS AND METHODS}

Experimental clay samples were collected from the Chanchaga clay deposit in Minna, Niger State of Nigeria, while sand samples were sourced from Kowa quarters, Jos, Plateau State of Nigeria. From each of the selected locations, samples of clay and sand materials were collected from ten different points, mixed thoroughly, and a representative sample taken by cone and quartering method for experimentation, as described by the AFS Mould and Core Test Handbook [4]. All samples were then dried in an oven at $110^{\circ} \mathrm{C}$ for two hours. Both clays and sands were ground and sieved through sieve aperture $1.40 \mathrm{~mm}$ in order to remove foreign particles. The cereal binder was extracted from alikama purchased from a local market in Minna, and prepared into a gelatinised form. Moisture, clay, and cereal contents were weighed and added to the sand mixes in varying proportions, while their moulding and core-making properties were monitored.

Four different sand mixes - A, B, C, and D, containing $5 w t \%, 6 w t \%, 7 w t \%$ and $8 w t \%$ clay binder respectively - were prepared. Each of the mixture containers weighed $800 \mathrm{~g}$, and were then further sub-divided into five portions of $160 \mathrm{~g}$ each, containing 1 to $5 \mathrm{wt} \%$ cereal binder and $5 \mathrm{wt} \%$ moisture. By means of universal sand tester, and using AFS standard procedure, five of the prepared specimens were tested for each of the following properties: bulk density (at 3, 4, and 5 ramming impacts), green compression strength and toughness (calculated as shown in equation 1), dry compressive and shear strength, baked strength, baked hardness, baked permeability, and baked collapsibility as described in AFS Mould and Core Test Handbook [4]. The various tests used the $\varnothing 50 \mathrm{~mm} \times 50 \mathrm{~mm}$ cylindrical AFS specimen, prepared by subjecting a weighed quantity of sand mould and core mixes to ramming blows that were adjusted to produce a close tolerance specimen, which was expelled from the tube on to a striping post. Freshly-made specimens were used for green properties testing, such as green compression strength and green toughness. Moisture content varying between 3 and $7 \mathrm{wt} \%$ was added to the mixes having optimum green 
properties from above, in order to optimise the green compression strength and green toughness. Dry properties were determined for specimens dried in the oven at $110^{\circ} \mathrm{C}$ for two hours, whereas for baked permeability, strength, and hardness, specimens were baked in a furnace for $230^{\circ} \mathrm{C}$ at 2.5 hours (Olakanmi and Khan [1]). The baked collapsibility was determined by loading standard AFS specimens into the collapsibility testing machine with an in-built furnace heated to $600^{\circ} \mathrm{C}$ and by soaking them at that temperature for about eight minutes (AFS Mould and Core Test Handbook [4]). Thereafter the time taken to rupture was recorded. These entire procedures were repeated five times for mixes containing varying amounts of cereal binder, clay binder, and moisture contents.

The green toughness was calculated as a percentage of the total weight of the fractured sand specimen that remained on the test sieve.

Shatter index or toughness $=\left(\mathrm{W}_{1} / \mathrm{W}_{2}\right) \times 100 \%$.

Where $W_{2}$ is the weight of specimen and $W_{1}$ is the weight of sand remaining on the sieve.

\section{RESULTS}

\subsection{Bulk density}

The relationship between the bulk density of the sand mixes containing $5 \mathrm{wt} \%$ moisture and the cereal content for varying clay contents and different numbers of ramming impacts is shown in Figures $1 \mathrm{a}, \mathrm{b}$, and c. It is evident that the bulk density of the moulding sand mixes increases as cereal content increases for a given clay content and number of ramming impacts. For example, the addition of $1 \mathrm{wt} \%$ cereal binder to the sand mix containing $5 \mathrm{wt} \%$ clay and $5 \mathrm{wt} \%$ moisture resulted in a bulk density of $1.37 \mathrm{gcm}^{-3}$ when the samples were rammed five times (Figure 1a). With an increase in the cereal binder to $5 \mathrm{wt} \%$ at the same clay and moisture contents and ramming impact, the bulk density had consequently increased to $1.58 \mathrm{gcm}^{-3}$ (Figure 1a). At $8 \mathrm{wt} \%$ clay content, the variation of the bulk density with the content of the cereal binder in the sand mix appeared to have followed a trend similar to that observed for the mixes containing $5 \mathrm{wt} \%$ clay and $5 \mathrm{wt} \%$ moisture. Therefore the bulk density is found to have increased as the clay content increased for corresponding cereal binder content in the sand mixes (Figure 1a, b, and c). Furthermore, comparison of the bulk density at a varying number of ramming impacts for the same cereal and clay binders content reveals that the bulk density decreases as the number of ramming impacts decreases. For instance, bulk density values were $1.68,1.63$, and $1.60 \mathrm{gcm}^{-3}$ at 5,4 , and 3 ramming impacts when cereal, moisture, and clay contents of the sand mixes were 5, 5, and $8 \mathrm{wt} \%$ respectively (Figure 1a, b, and c). Observation of error bars in Figure 1 reveals that variation in measurements is not significant for the bulk density.

\subsection{Green compressive strength and toughness}

Figures $2 \mathrm{a}$ and $3 \mathrm{a}$ reveal that the optimum green compressive strength and toughness occur at $3 w t \%$ cereal content, irrespective of the fact that the clay content in the moulding sand mixes has $5 \mathrm{wt} \%$ moisture content. In addition, optimum green compressive strength and toughness are noted to have increased with increased clay content, as shown in Figure 2a and $3 \mathrm{a}$ respectively. When the variations of green compressive strength and toughness of the mixes with moisture content were investigated, both green compressive strength and toughness were noted to have been optimised at the point where it contained $5 \mathrm{wt} \%$ moisture (Figures 2b and $3 \mathrm{~b}$ ).

Meanwhile, green compressive strength and toughness of the mixes increase as moisture content increases from 3 to $5 \mathrm{wt} \%$, and then as the moisture content increases beyond $5 \mathrm{wt} \%$ (Figure 2b). Therefore, the highest green compressive strength $\left(66 \mathrm{kNmm}^{-2}\right)$ for the mixes occurred when it contained $5 \mathrm{wt} \%$ moisture, $8 \mathrm{wt} \%$ clay, and $3 \mathrm{wt} \%$ cereal binder. This corresponds to the highest green toughness of $85 \%$ (Figure $3 \mathrm{~b}$ ). Observation of error bars in 
green compressive strength (Figure 2) and toughness (Figure 3 ) of the samples indicates that variation in measurements is not significant.

(a)
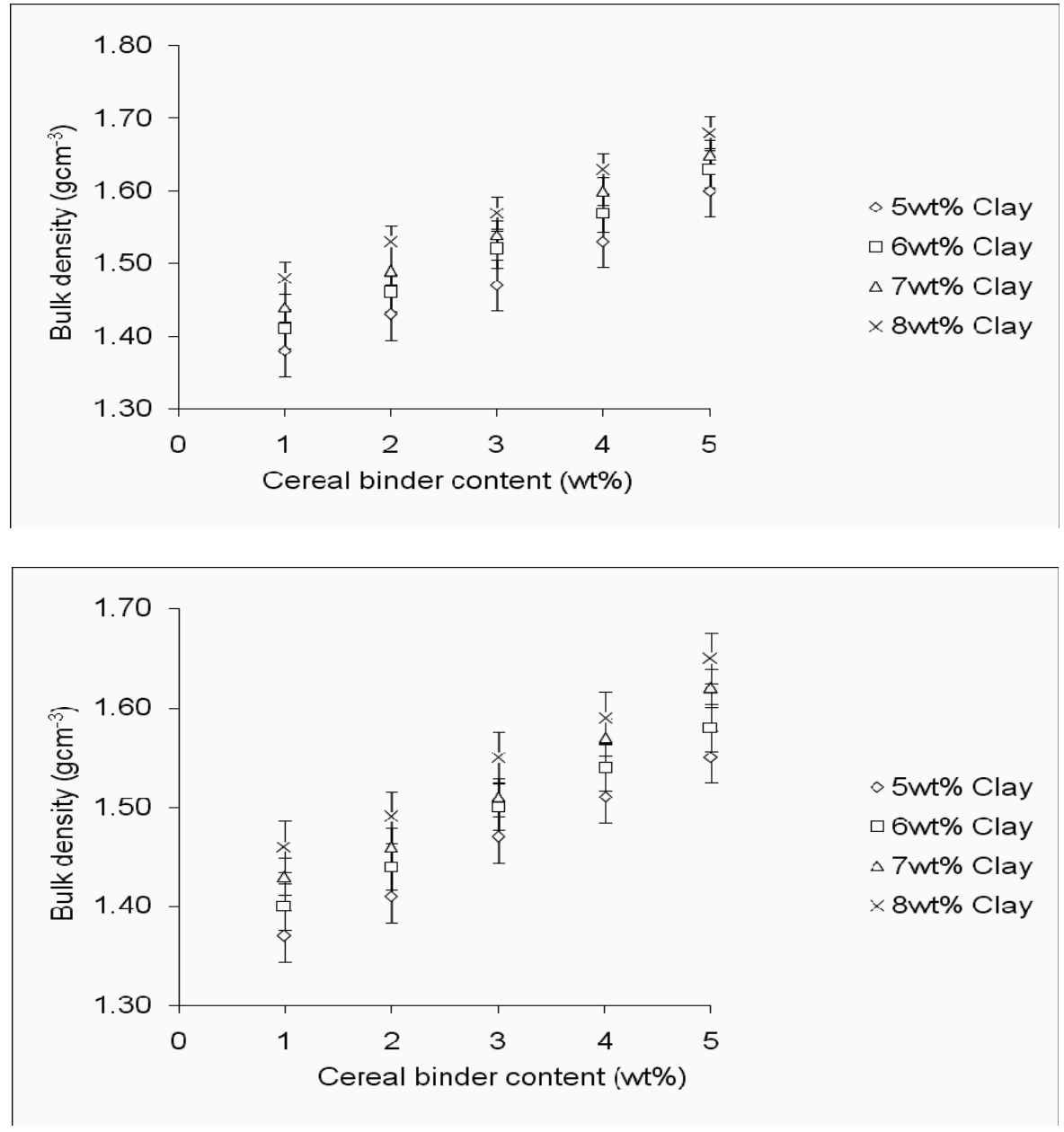

(b)

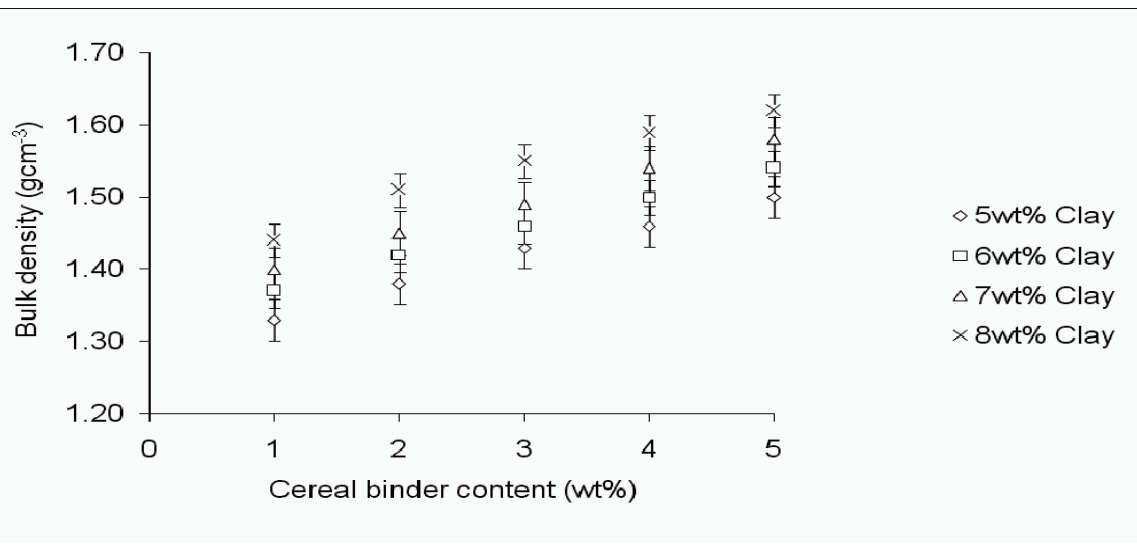

Figure 1: Variation bulk density of the sand mixes containing $5 \mathrm{wt} \%$ moisture with varying cereal and clay binders' content at (a) 5 ramming impacts, (b) 4 ramming impacts, and (c) 3 ramming impacts 


\subsection{Dry compressive, dry shear, and baked strengths}

The results of the dry compressive, dry shear, and baked strengths of the sand mixes prepared in varying proportion of cereal and clay binders' contents are presented in Figures $4 a, b$, and $c$ respectively. Figure $4 a$ shows that the dry compressive strength increases as both the cereal and clay contents increase. Likewise, the variation of the dry shear strength with cereal content in the sand mixes follows the same pattern as that of dry compressive strength for given clay content (Figure 4b). Again, the dry shear strength increases as the clay content in the sand mixes increases (Figure 4b). Figure 4c shows that the baked strength values of the sand mixes increased initially, and was eventually optimised at 3wt\% cereal binder content.

(a)
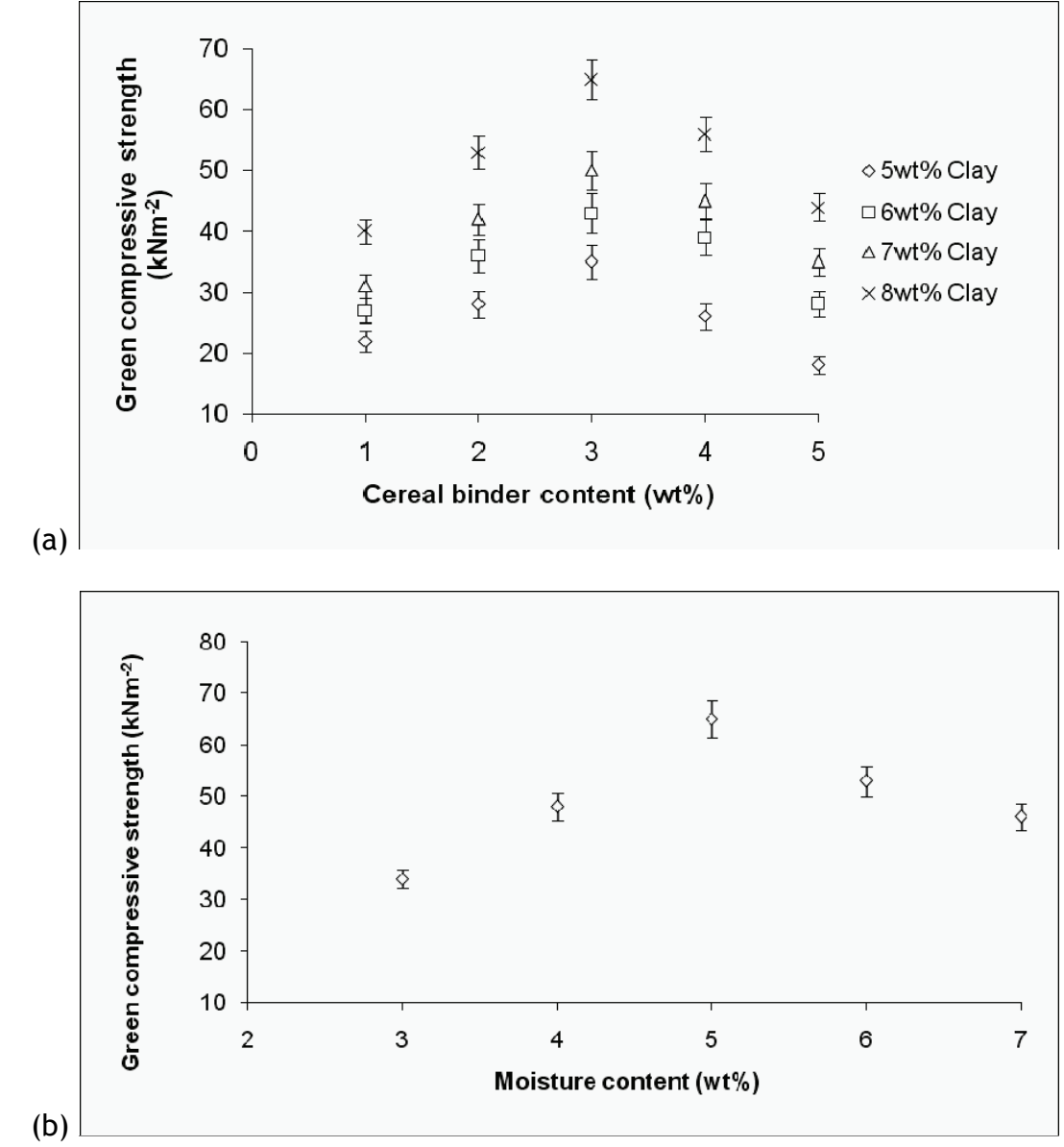

Figure 2 (a) Variation of the green compressive strength of the mixes containing $5 \mathrm{wt} \%$ moisture with the cereal binder content and different clay contents; (b) Variation of the green compressive strength with the moisture content for the sand mixes containing $5 \mathrm{wt} \%$ cereal binder, and $8 \mathrm{wt} \%$ clay contents

Further increment in the cereal binder content beyond $3 \mathrm{wt} \%$ consequently produced reduction in the baked strength property of the sand mixes. Figure 5 shows that both dry compressive and shear strengths increase as the moisture content increases in the sand mixes. Meanwhile, error bars in Figures 4 and 5 suggest that variation in measurements of dry compressive, dry shear, and baked strengths in all the samples is not significant. 
(a)
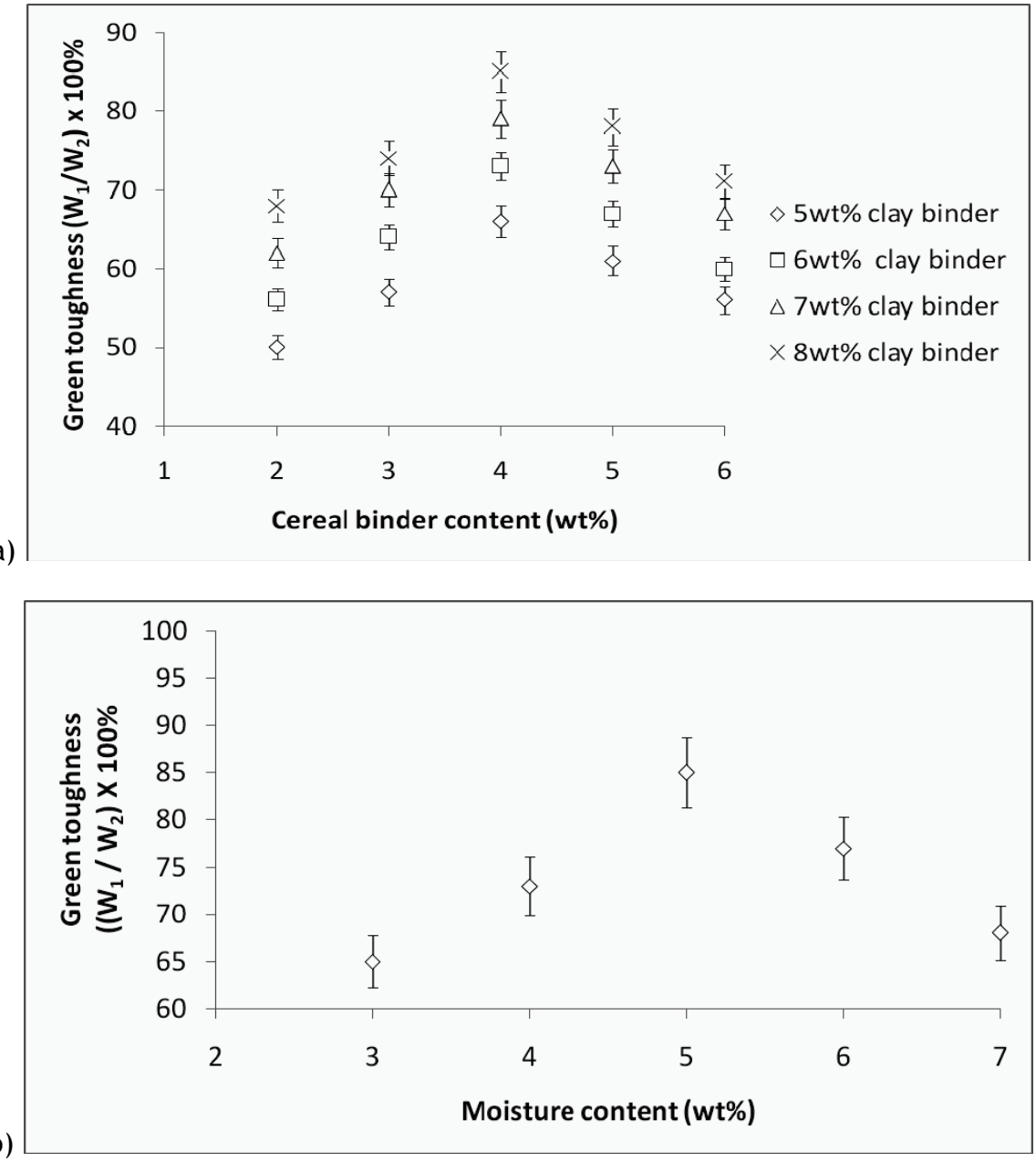

Figure 3: (a) Variation of the green toughness of the mixes containing $5 \mathrm{wt} \%$ moisture with the cereal binder content and different clay contents; (b) Variation of the green toughness with the moisture content for the sand mixes containing $5 \mathrm{wt} \%$ cereal binder, and $8 \mathrm{wt} \%$ clay contents

\subsection{Baked hardness, permeability, and collapsibility}

Figure 6a shows that the baked hardness of the sand mixes increases with the cereal binder content for given clay content when the sand mixes contain $5 \mathrm{wt} \%$ moisture. As an illustration, for a sand mix containing $6 \mathrm{wt} \%$ clay, baked hardness values obtained were 70 , 76 , and $87 \mathrm{CH}$, for 2,3 , and $5 \mathrm{wt} \%$ cereal binder contents respectively at fixed moisture content of $5 \mathrm{wt} \%$ (Figure 6a). Again, the baked hardness of the sand mixes is seen to be increasing from 69 to $85 \mathrm{CH}$ as the clay content increases from 5 to $8 \mathrm{wt} \%$ for $3 \mathrm{wt} \%$ cereal binder content (Figure 6a).

The baked permeability of the sand mixes could be seen to be increasing as the cereal binder content increases, as shown in Figure $6 \mathrm{~b}$ for given clay content when the sand mixes contain $5 \mathrm{wt} \%$ moisture. Baked permeability could be seen to be reducing as the clay content increases (Figure 6b). In Figure 6c, the baked collapsibility of the mixes is seen decrease as the cereal binder decreases, whereas it increases as the clay content increases. Finally, error bars in Figures 6a, b, and c suggest that variation in measurements of baked hardness, permeability, and collapsibility in all the samples is not significant. 


\section{DISCUSSION OF RESULTS}

\subsection{Bulk density}

The increment noted in the bulk density of sand mixes as its cereal binder content increases (Figure 1) could be attributed to the ability of the cereal binder to form gelatinous bonds when moisture is added to the sand mixes (Beeley [5], Jain [6]). The formation of gelatinous bonds enables the constituent particles of the sand mixes (e.g. clay) to bind together more effectively. It is evident from the results obtained from Figures $1 \mathrm{a}$ to $\mathrm{c}$ that the higher the number of ramming impacts for sand mixes containing a fixed amount of cereal and binders, the closer the sand particles in the mixes pack together; hence the increment obtained in the bulk density. Therefore it can be inferred that both the cereal binder content and the number of ramming impacts influence the bulk density of the sand mixes. Comparison of bulk density values obtained in Figure 1a - for sand mixes containing different clay amounts when the number of ramming impact is fixed at five appears to validate the speculation that the bulk density increases with the cereal binder content as well as the clay content in the mixes.

Meanwhile, careful observation of Figures $1 a, b$, and $c$ indicates that the effects of the number of ramming impacts and clay content on the bulk density of the samples are smaller compared with the bulk density values obtained when the cereal binder contents were varied. For example, bulk densities increased from 1.60 to $1.68 \mathrm{gcm}^{-3}$, representing a $5 \%$ increment, when the number of ramming impact was varied from three to five for a sample containing $5 \mathrm{wt} \%$ cereal and $8 \mathrm{wt} \%$ clay binders. Likewise, an increment of $5 \%$ in bulk density was obtained for samples containing $5 \mathrm{wt} \%$ to $8 \mathrm{wt} \%$ clays, $5 \mathrm{wt} \%$ cereal binders, and subjected to five ramming impacts.

These variations in bulk density are smaller when compared with the $13.5 \%$ increment in bulk density obtained for samples containing 1 to $5 \mathrm{wt} \%$ cereal binder and $8 \mathrm{wt} \%$ clay binder subjected to five ramming impacts. However, the consistent correlation between number of impacts and the test metrics, even though small, confirms the validity of the test results. Considering the sensitivity of the samples' bulk densities to the number of ramming impacts, further tests employing higher numbers of ramming impacts may be required to establish if significant variation in bulk densities of samples could be obtained for constant clay and cereal binders' content.

Meanwhile, comparison of the optimum bulk density $\left(1.68 \mathrm{gcm}^{-3}\right)$ obtained from this study with the outcome $\left(1.55 \mathrm{gcm}^{-3}\right)$ from the study of Ibitoye and Afonja [3] indicates that alikama cereal binder is able to impart improved bulk density to the moulding and core mixes, given that a significantly higher clay content $(75 \mathrm{wt} \%)$ blended with $3 \mathrm{wt} \%$ starch binder in the sand mixes was required to achieve a similar result in the investigation conducted by Ibitoye and Afonja [3]. 
(a)

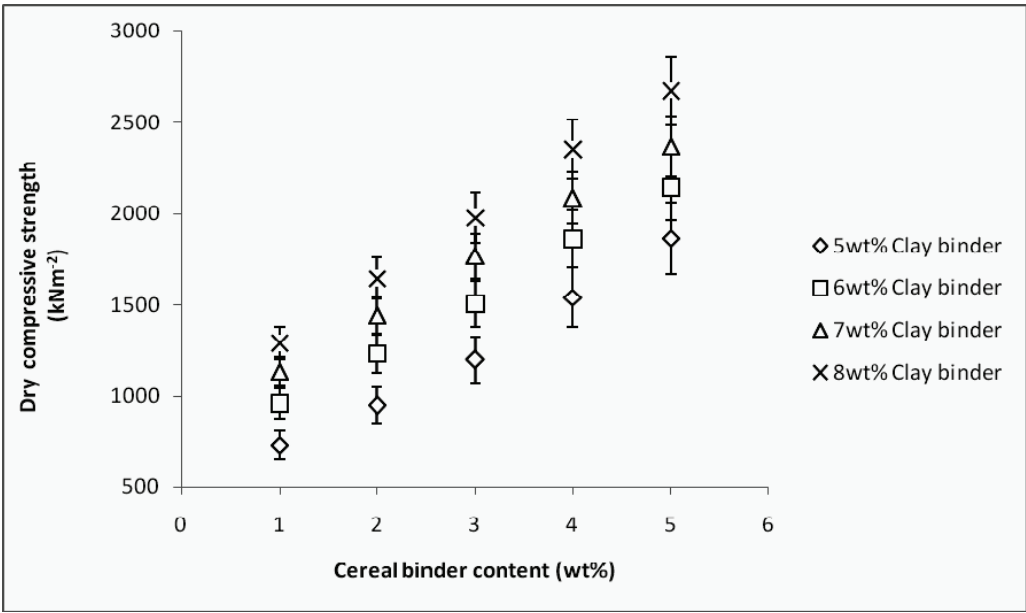

(b)

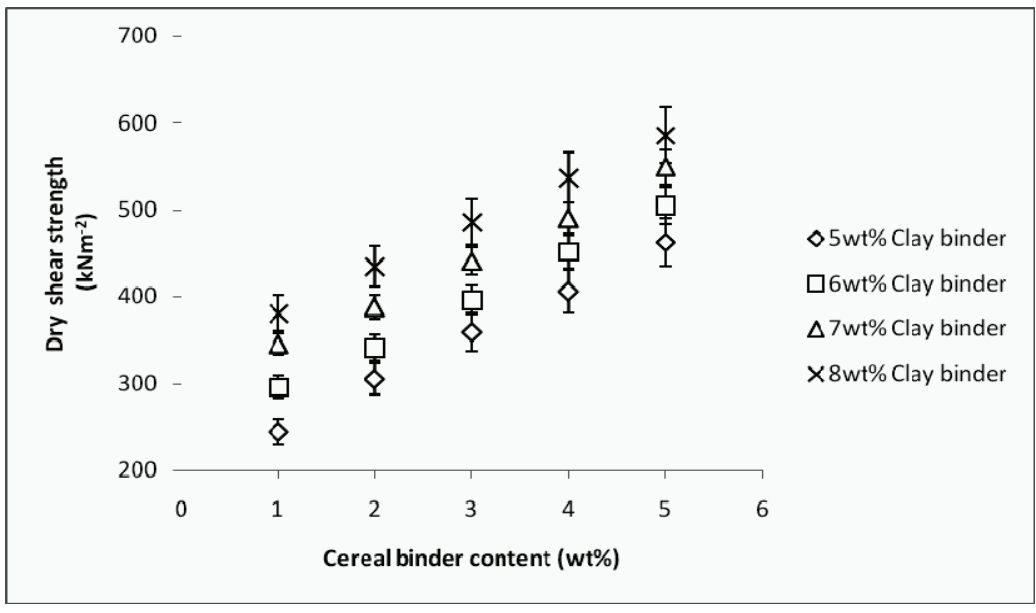

(c)

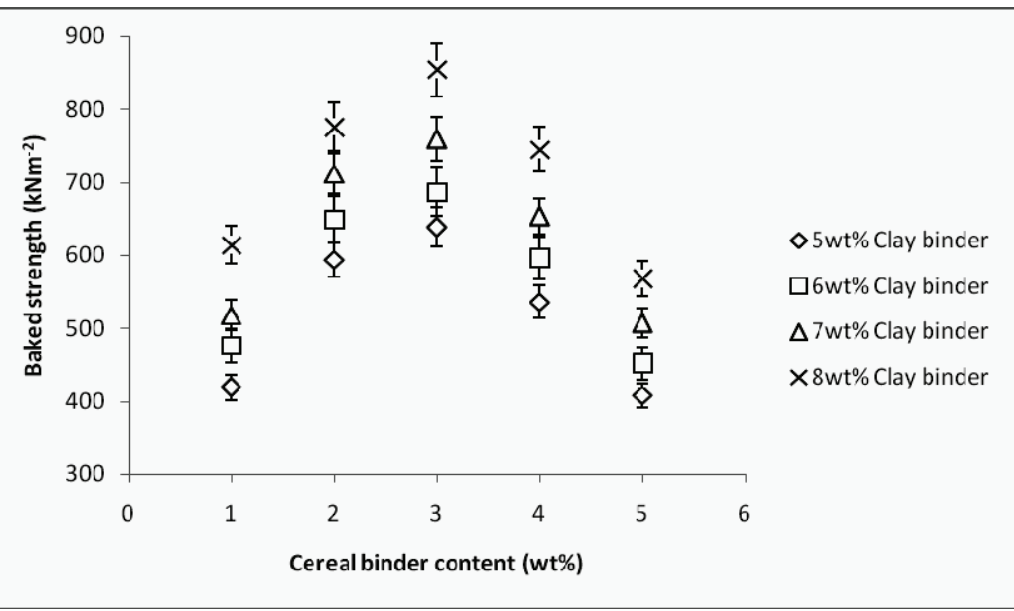

Figure 4: Variation of (a) dry compressive strength, (b) dry shear strength, and (c) baked strength with the cereal binder content and different clay contents in the sand mixes containing $5 \mathrm{wt} \%$ moisture 


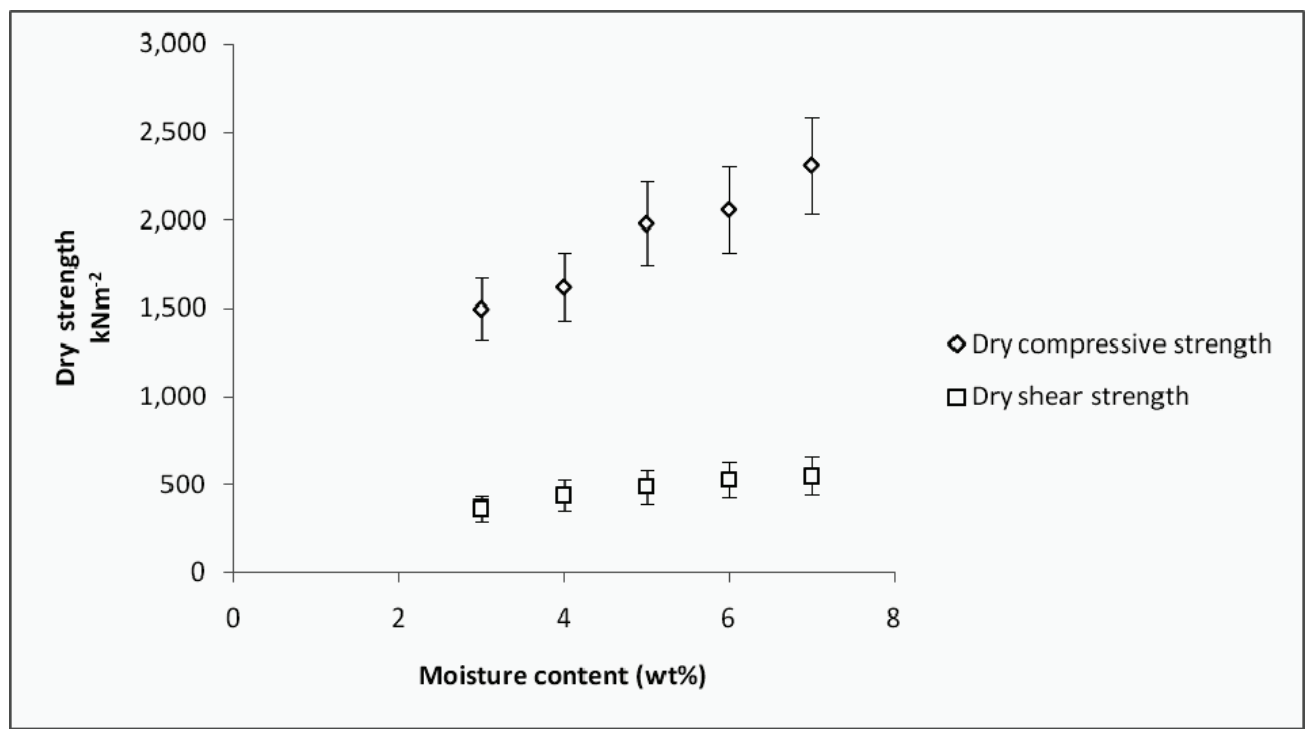

Figure 5: Variation of (a) dry compressive strength, and (b) dry shear strength, with the moisture content in the sand mixes containing $3 \mathrm{wt} \%$ cereal binder, $8 \mathrm{wt} \%$ clay binder

On the basis of the foregoing analysis, it may be suggested that the degree of binding of the sand mixes indicated by the bulk density is mainly a function of the cereal binders' content, provided that the mixes contain an optimum clay amount and encounter optimum ramming action.

\subsection{Green compressive strength and toughness}

The addition of cereal binder to the sand mixes is informed by the need to increase its green strength through the formation of the gelatinous bond upon the addition of moisture. Moreover, cereal binder is expected to improve the collapsibility of the moulding samples made from the sand mixes upon exposure to the heat of the castings. The optimisation of green compressive strength when the sand mixes contain $3 \mathrm{wt} \%$ cereal binder, $8 \mathrm{wt} \%$ clay binder, and $5 \mathrm{wt} \%$ moisture (Figures 2 and 3 ) could be explained by the formation of the highest gelatinous green compressive bond strength indicated by $66 \mathrm{kNmm}^{-2}$ (Figure 2) (Loto [2]). The cereal binder possesses an affinity for polar substrates; therefore it is able to form a gelatinous bond with moisture as noted earlier. For a typical sand mix, there are optimal cereal binder and moisture content. For example, too much cereal binder and moisture content could result in excessive plasticity, and quantities less than the optimal values tend to develop insufficient bond strength for the sand grains in the mixes.

Therefore it could be argued that the suggested mechanism for the development of green strength in the sand mixes is a function of polar properties of the cereal binder by which they are able to adsorb strong polar molecules, especially water molecules. It is thought that the adsorption results in the formation of thin water layers around the molecules of the cereal binder, and that this accounts for the plasticity of the sand mixes.

The increament in the optimum green compressive strength obtained as the clay content increased could be ascribed to the possibility that increased clay content in a sand mix promote its ion exchange capacity, thus increasing the bonding property of the sand mix. 
(a)

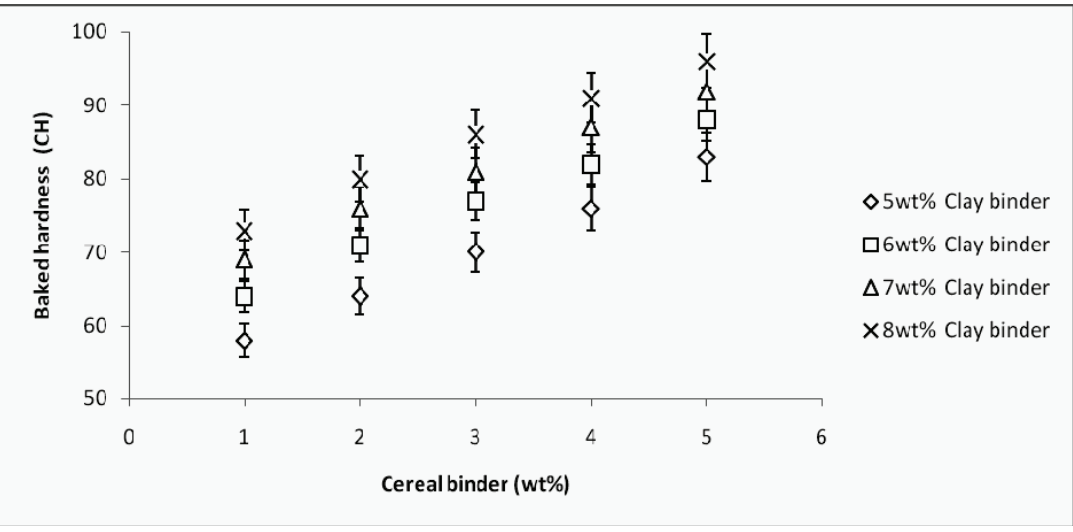

(b)

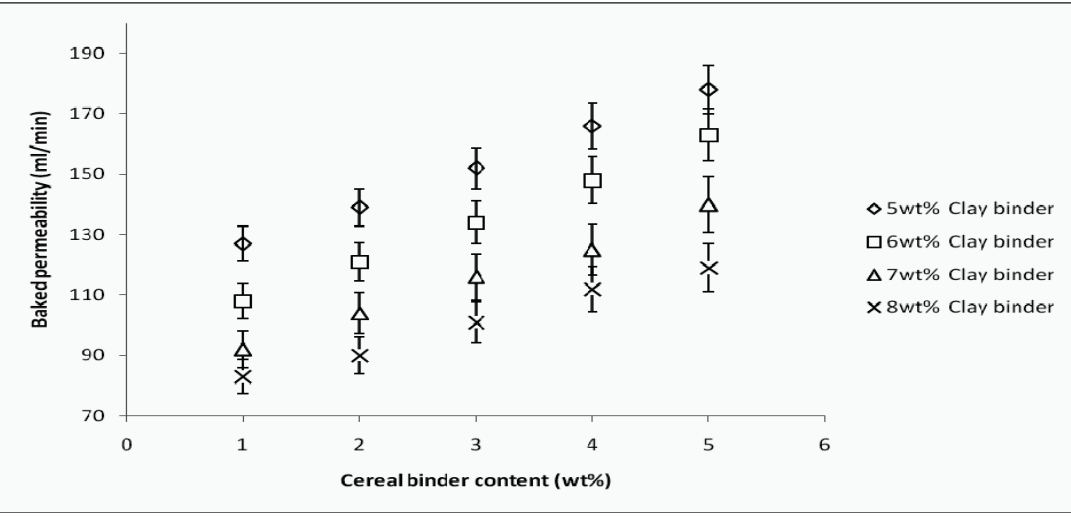

(c)

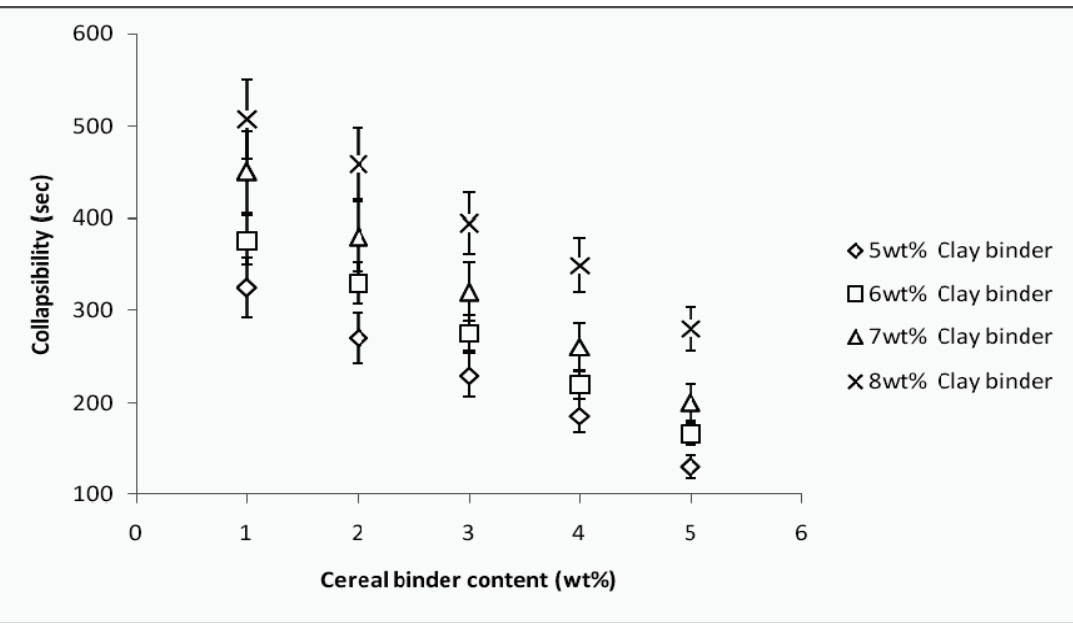

Figure 6: Variation of (a) baked hardness, (b) baked permeability, and (c) collapsibility with the cereal binder content and different clay contents in the sand mixes containing $5 w t \%$ moisture

Optimum green compressive strength obtained from this research is found to be within the range of values (41 to $70 \mathrm{kNm}^{-2}$ ) suitable for steel and grey iron castings suggested by Beeley [5], Jain [6], and Anon [7]. Furthermore, the optimum green compressive strength obtained from this study is comparable to that derived from Olakanmi [1], in which green compressive strengths of 70.0, 68.0, and $48.0 \mathrm{kNm}^{-2}$ were recorded for Oniboki, River Asa, 
and Bacita sands respectively when $5 \mathrm{wt} \%$ bentonite binder was added to each sand sample. However, the optimum green strength value obtained in this study is noted to be lower than that $\left(102 \mathrm{kNm}^{-2}\right)$ obtained from the study of Loto [2] when $0.3 \mathrm{wt} \%$ cassava starch, $13 \mathrm{wt} \%$ clay, and $3 w t \%$ moisture were added to the moulding sand mixes. The significant discrepancy in the results obtained could be attributed to the difference in the mixes' composition used in the two studies. Furthermore, the attainment of such a high green compressive strength when only $0.3 \mathrm{wt} \%$ cassava starch was added to the moulding mixes need to be investigated further in order to understand the nature of its bonding mechanism.

Shatter index is a measure of sand toughness, a property that aids satisfactory lift during pattern withdrawal. Shatter index values should fall within the mouldable range of $50 \%$ to 85\% (Davies [9]). A value below this range suggests fragility in pattern withdrawal and subsequent handling operations, whereas a high value outside this range indicates unsatisfactory moulding qualities as a consequence of excessive moisture.

By comparing the green compressive strength of the sand mixes to its green toughness, it could be argued that the toughness of the clay-bonded sand mixes increases as the green compressive strength of the sample increases. This behaviour could be explained by the mechanism of an optimum condition being reached in the sand-clay-cereal-water saturation system. The excess or inadequate moisture/cereal binder increases the plasticity, which makes the clay sample easily deformable - hence a decrease in toughness with an attendant increase in collapsibility. Meanwhile, collapsibility determines the fragility of the moulding sand, and it is the inverse of toughness; thus its tendency to increase with low green strength of clay-bonded sand could be validated.

Furthermore, the relationship between the green toughness of the sand mixes on the one hand and the cereal binder and moisture contents on the other hand is similar to that existing between the green compressive strength of the sand mixes and the cereal binder and moisture contents (see the previous paragraph). It is clear that both green toughness and compressive strength of the sand mixes are optimised when it contains $3 \mathrm{wt} \%$ cereal binder, $8 \mathrm{wt} \%$ clay binder, and $5 \mathrm{wt} \%$ moisture contents (Figures $2 \mathrm{a}$ and $\mathrm{b}$ ). On this basis, the green toughness behaviour of the sand mixes can be explained by the same mechanism responsible for the optimisation of bond strength, which is dependent on the polar properties of the cereal binder by which they are able to adsorb strong polar molecules, especially water molecules (see above). Meanwhile, green toughness of sand mixes containing $3 \mathrm{wt} \%$ cereal binder, $5 \mathrm{wt} \%$ moisture, and $8 \mathrm{wt} \%$ clay contents is found to be comparable to the recommended mouldable range of 50\% to $85 \%$ (Davies [9]). Moreover, the optimum green toughness of $85.0 \%$ obtained from this study is comparable to that derived from Olakanmi [8], in which green toughness of $83.0 \%$ and $85.0 \%$ were recorded for River Chanchaga and lgbokoda sands respectively when $5 \mathrm{wt} \%$ bentonite binder was added to each sand sample. Meanwhile, Loto [2] discovered that the addition of cassava starch to the moulding mixes decreased its toughness, contradicting the finding of this study. However, concurring with Loto [2], the rationale for his observation might be the non-optimisation of the moisture content. Therefore, moisture content used in his study might have been inadequate for the cassava starch to contribute to the toughness of the moulding sand mixes.

\subsection{Dry compressive, dry shear, and baked strength}

A mould of low dry strength has poor resistance to metallostatic pressure of the falling molten metal. On the other hand, a mould of extremely high dry strength will be adversely affected by the problem of poor collapsibility during the removal of solidified castings although it is advantageous in producing a dimensionally stable casting. It could be seen that the dry compressive and shear strengths increased significantly for all samples with varying cereal binder contents (Figures $4 a$ and b). Moreover, it is clear that dry compressive and shear strengths increase for sand mixes containing 3wt\% cereal and $8 \mathrm{wt} \%$ clay binders, irrespective of their moisture contents (Figure 5). Significant improvements obtained in the 
dry compressive and shear strengths are expected, and this could possibly be attributed to improved distribution of the cereal and clay binders and the higher bulk densities attainable (Beely [5]). The dry compressive strengths of the samples increased irrespective of their moisture content. Meanwhile, differences in moisture contents of the clays could be said not to be primarily accountable for the significant increase in dry compressive and shear strengths.

According to Caine and Toepke [10], a potential cause of bond strength is the surface tension of the water surrounding the cereal binder, the clay binder, and sand-clay particles and filling the capacity interstices, particularly those of the clay particles. Therefore, it suggests that the bond strength is a consequence of the surface layers of water acting on a stretched membrane, thereby forcing the particles together. However, Taylor et al. [11] argued that, with the water layer becoming thinner by drying, the forces holding the particles together increase, thus increasing the dry compressive strength of the moulding sand mixtures significantly above than their green strength. It seems that this occurs as a result of cereal/clay saturation for the given water content fracture on the stretched interparticle membrane, which easily disrupts and breaks up the polar bonds.

The baked strength of the sand mixes is noted to have been optimised at the point where it contained 3wt\% cereal binder (Figure 4c). Subsequent increase in the cereal binder content above $3 \mathrm{wt} \%$ resulted in a reduction of the baked strength. Again, this behaviour may be accounted for by the evaporation of moisture at $230^{\circ} \mathrm{C}$ from the gelatinous bond formed initially by the cereal binder in the sand mixes in the presence of moisture. Consequently, upon the evaporation of all the moisture from the sand mixes, it is thought that the clay and the remains of the burnt-off cereal contents might be responsible for binding together the sand grains in the mixes. Since the clay content was not varied, the possibility is that a reduction or increment in baked strength could only have been influenced by varying contents of the cereal binder in the sand mixes. This explanation could be supported by the fact that, with the cereal binder content not exceeding $3 \mathrm{wt} \%$, cereal binder film surrounding the sand particles is thought to have enhanced the bonding efficiency, as indicated by the baked strength. Beyond the optimum cereal binder content of $3 \mathrm{wt} \%$, it is possible the cereal binder film surrounding the sand grains in the mixes becomes thicker, and the distance between the neighbouring grains increases. Consequently, upon baking, a weak bond is thought to have been formed between the neighbouring particles, and this resulted in reduced baked strength. An alternative possibility that may account for the result obtained is that the binding efficiency of the cereal binder might have been completely lost at the baking temperature of $230^{\circ} \mathrm{C}$. As a result, the cereal binder molecules are thought to have behaved like sand grains, thereby requiring additional clay binder. Since the clay content in the sand mixes is held constant, weak points are formed as the cereal binder content increases, resulting in the reduction in the baked strength when the cereal binder content exceeds $3 \mathrm{wt} \%$. Meanwhile, values of dry compressive, dry shear, and baked strengths obtained for the optimum mix in this study are found to be comparable with those used in the foundries for light to heavy iron castings and non-ferrous castings (Beeley [5], Jain [6], and Anon [7]). The optimum dry and baked strengths obtained from this study are found to be comparable with those derived for locally available sand samples tested for the moulding and core-making properties in Olakanmi and Khan [1], when $5 \mathrm{wt} \%$ bentonite binder was added to each sand sample.

\subsection{Baked hardness, permeability, and collapsibility}

The baked hardness of the sand mixes is seen to increase as both the cereal and clay contents increase (Figure 6a). The values obtained $(95 \mathrm{CH})$ for the sample containing $3 \mathrm{wt} \%$ cereal binder content and $8 \mathrm{wt} \%$ clay content conformed to that $(95 \mathrm{CH})$ recommended by Heine et al. [12] for large ferrous castings that require hard cores.

The increase in the baked permeability of the sand mixes as the cereal binder content increases hinges on the possibility that the combustion of the cereal binder content during the baking process results in the formation voids in the specimens. Therefore more voids 
are created during the baking process at a high temperature $\left(230^{\circ} \mathrm{C}\right)$ as more cereal binders are added to the sand mixes. This explanation suggests that the increase in the number of voids existing in the baked samples as the cereal binder content increases is evident from the higher permeability values obtained in Figure 6b. The reduction in permeability (Figure 6b) observed for sand mixes containing higher clay content could be attributed to the noncombustible nature of the clay binders, which is thought to have retained its bonding strength (at high temperature), and which is responsible for binding the sand grains together.

The reduction of the baked collapsibility of the sand mixes as the cereal binder content increases in Figure $6 \mathrm{C}$ could probably be explained by the high temperature $\left(650^{\circ} \mathrm{C}\right)$ combustion of the cereal binder and other organic materials contents. The process of combustion is thought to have resulted in the ease with which the sand mixes collapsed during baking. Meanwhile, the collapsibility values obtained for the sand mixes is seen to have increased with clay content at a fixed cereal binder content (Figure 6c). According to Dietert [13], collapsibility within the range of 60 to 120 seconds is considered as fast, with the consequence of the production of cracks and warpage in castings; whereas those greater than 480 seconds are regarded as slow, thus resulting in metal penetration into castings. However, moderate collapsibility of 400 s (Figure $6 \mathrm{c}$ ) (between fast and slow) that was recorded in this study for core sand mixes containing $3 \mathrm{wt} \%$ cereal binder content, $8 \mathrm{wt} \%$ clay content, and $5 \mathrm{wt} \%$ moisture content is considered to be suitable for sand castings. Finally, the baked hardness, permeability, and collapsibility obtained for the optimum sand mix in this study are comparable to those derived for locally available sand samples tested for moulding and core-making properties in Olakanmi and Khan [1] when 5wt\% bentonite binder was added to each sand sample.

\section{CONCLUSIONS}

The outcome of this work suggests the viability of the cereal binders' addition in a clay bonded core and moulding sand mixes for industrial and laboratory applications. This is evident in the results obtained for the green compressive strength, toughness, dry compressive and shear strengths, baked strength, hardness, permeability, and collapsibility, which are comparable to values obtained from the literature when $3 \mathrm{wt} \%$ cereal, $8 \mathrm{wt} \%$ clay binder, and $5 \mathrm{wt} \%$ moisture are contained in the sand mixes. It is discernible from this study that the green properties and baked strength were optimised at the point where the sand mixes contain $3 w t \%$ cereal binder. Moreover, addition of the cereal binder to the sand mix increased the bulk density and baked hardness, and reduced the collapsibility of the samples. Finally, the use of cereal binder in the clay bonded sand mixes imparts functional properties that are comparable to those obtained when using the imported bentonite clay. Thus alikama cereal binder, combined with Chanchaga clay bonded sand mixes, could be used as a substitute for the imported bentonite. In order to establish the viability of the alikama cereal binder combined with Chanchaga clay bonded sand mixes as suitable foundry materials, further work is needed to demonstrate examples of these materials in actual castings. This shall entail the determination of the suitability of the mixes for small, medium, and large castings, as well as their effect on defect formation in the castings.

\section{ACKNOWLEDGEMENT}

The authors wish to acknowledge the assistance and contributions of staff members at the foundry sections of Nigeria Machine Tools, Osogbo, Osun State; National Metallurgical Centre (NMDC), Jos, Plateau State; and National Mineral Development Corporation (NMDC), Jos, Plateau State, Nigeria, in gathering the experimental data for this study.

\section{REFERENCES}

[1] Olakanmi, E.O. \& Khan R.H. 2002. Investigation of the moulding and core-making properties of some locally available foundry sands, Journal of Science, Technology, and Mathematics Education, 5 (2), pp. 67-75. 
[2] Loto, C.A. 1990. Effect of cassava flour and coal dust additions on the mechanical properties of a synthetic moulding sand, Applied Clay Science, 5, pp. 249-263.

[3] Ibitoye, S.A. \& Afonja, A.A. 1996b. Effect of starch addition on the bulk density, baked hardness, and collapsibility of potter's clay-bonded sands, Ife Journal of Technology, 6 (1), pp. 35-42.

[4] American Foundrymen's Society Inc. 1963. Mould and core test handbook, $7^{\text {th }}$ edition, New York.

[5] Beeley, P.R. 2001. Foundry technology, $2^{\text {nd }}$ edition, London, ButterworthHeinemann.

[6] Jain, P.L. 2003. Principles of foundry technology, $4^{\text {th }}$ edition, New Delhi, Tata McGraw Hill Publishing Company.

[7] Anon 1962. Moulding materials and methods. $1^{\text {st }}$ edition, AFS, Chicago.

[8] Olakanmi, E.0. 2001. Characterisation of the locally available sands for moulding and core-making purposes. Unpublished M. Eng. thesis, Department of Mechanical Engineering, Federal University of Technology, Minna, Nigeria.

[9] Davies, W. 1950. Foundry sand control. Testing Research Department, United Steel Companies, Humphries Limited, London.

[10] Caine, J.B. \& Toepke, R.E., 1968. Water-bond ratios and mouldability of molding sands, Am. Foundrymen Soc. Trans., 76, pp. 65-69.

[11] Taylor, F.H., Fleminas, M.C. \& Wulff, J., 1966. Foundry engineering. Wiley, New York.

[12] Heine, R.W., King, E.H., \& Schumacher, J.S. 1958. Correlation of green strength, dry strength, and mould hardness of moulding sands, Am. Foundrymen's Soc. Trans., 66, pp. 59.

[13] Dietert, H.W. 1950. Foundry core practice, American Foundrymen's Society. 
http://sajie.journals.ac.za 